\title{
Geociências
}

\section{Estudo computacional do mecanismo de tombamento flexural em filitos}

\author{
Marcus Vinícius Diláscio \\ Coord. de Projetos - GOLDER ASSOCIATES BRASIL \\ e-mail:mdilascio@golder.com.br \\ Rodrigo Peluci de Figueiredo \\ Professor Adjunto, Departamento de Engenharia de Minas \\ Prog. Pós-Graduação de Engenharia Civil/Geotecnia, EM/UFOP
}

\section{Resumo}

Taludes escavados em filito, sejam para obras civis ou de mineração, são conspícuos na região do Quadrilátero Ferrífero, MG. Em sua grande maioria, verifica-se a ocorrência de mecanismos de instabilização não usuais em taludes escavados em outros materiais rochosos, como, por exemplo, o tombamento flexural.

Foram realizadas 255 análises paramétricas, correspondendo a uma combinação de geometrias de talude com ângulos variando de $30^{\circ}$ a $60^{\circ}$ e alturas de 50 a 200 $\mathrm{m}$, de ângulos da foliação variando de $40^{\circ}$ a $80^{\circ}$, e de quatro diferentes classes geomecânicas de maciços.

Utilizou-se o método computacional de diferenças finitas implementado no software FLAC, que permite a consideração de grandes deformações do maciço analisado (o que pode ocorrer em um talude de filito/xisto), e é especialmente apto a modelar o processo dinâmico de instabilização de um talude.

Os resultados permitiram a criação de três cartas de estabilidade para as classes de maciço II, III e IV, com curvas que delimitam zonas estáveis e instáveis ao tombamento flexural, para diferentes alturas de talude. Tais cartas são adequadas para análises preliminares de projeto, nos taludes de filitos e xistos do Quadrilátero Ferrífero. Permitiram, ainda, uma melhor compreensão da mecânica do processo de instabilização de tais taludes.

Palavras-chave: tombamento flexural, taludes em filito, modelo computacional, FLAC.

\begin{abstract}
Slopes in phylite, of civil works or of mining, are conspicuous in the region of the Quadrilátero Ferrifero, $M G$. In the great majority it verifies the occurrence of instabilization mechanisms, such as flexural toppling, not usual in slopes of other rocky materials.

We used the computational method of finite differences implemented in the software FLAC who allows the consideration of great deformations of the analyzed massif (what it can occur in a slope of phylitel schist), and it is especially apt to model the dynamic process of instabilization of a slope.

They were accomplished 255 parametric analyses, corresponding to a combination of slopes geometries with angles varying from $30^{\circ}$ to $60^{\circ}$ and heights from 50 to $200 \mathrm{~m}$, of angles of the foliation varying from $40^{\circ}$ to $80^{\circ}$, and of four different geomechanical classes of massifs.

The results allowed the creation of three stability charts for the geomechanical classes II, III and IV, with curves that define stable and unstable zones of flexural toppling, for different heights of slope. Such charts are adequate for preliminary analyses of slopes designing, in phylites and schists of the Quadrilatero Ferrifero. The computational analyses allowed, yet, a better comprehension of the mechanics of the instabilization process of such slopes.
\end{abstract}

Keywords: flexural toppling, slopes in phylite, computational modeling, FLAC. 


\section{Introdução}

Taludes escavados em filito, sejam para obras civis ou de mineração, são conspícuos na região do Quadrilátero Ferrífero, MG. Em sua grande maioria, verifica-se a ocorrência de mecanismos de instabilização que não são usuais em taludes escavados em outros materiais rochosos, entre eles o tombamento flexural (flexural toppling).

Os métodos de análise, usuais para taludes rochosos, aplicáveis a mecanismos envolvendo movimentos de bloco rígido (cinemáticos e por equilíbrio-limite), não são inteiramente adequados para avaliar a estabilidade ao tombamento, em virtude do fato de decorrerem essencialmente da deformação da massa rochosa escavada, o que não é considerado nos métodos usuais.

Nesse artigo, apresentam-se os resultados de uma investigação do mecanismo de tombamento flexural através de análises tensões-deformações pelo método de diferenças finitas. Foi realizada uma análise paramétrica, variando não só os parâmetros de resistência do modelo analisado, mas também, a geometria do talude e da foliação para diferentes alturas de escavação.

\subsection{Mecanismo de tombamento flexural}

O tombamento flexural ocorre com mais freqüência em taludes escavados em rochas sedimentares estratificadas ou metamórficas foliadas, cujas direções da estratificação ou foliação são praticamente paralelas à direção do talude e mergulham em sentido oposto ao mesmo. Podem ocorrer também em outros litotipos, desde que contenham, pelo menos, uma família de descontinuidade que obedeça ao arranjo geométrico descrito anteriormente.

Devido à ação do próprio peso, uma série de lâminas rochosas delimitadas pelas descontinuidades pode, a depender do atrito entre elas, deslizar umas sobre as outras e fletir, levando a uma ruptura por tração na base da lâmina e, finalmente, ao tombamento das mesmas (Figura 1).
A condição cinemática de deslizamento das lâminas, para que o tombamento ocorra, foi definida por Goodman e Bray (1976). Segundo esses autores, com base no princípio de que a tensão de cisalhamento ao longo das descontinuidades deva exceder a resistência por atrito e, assumindo que a tensão principal máxima esteja orientada na direção paralela à face do talude, a condição de deslizamento das lâminas pode ser obtida por:

$\alpha \geq 90^{\circ}+\phi \mathrm{j}-\beta$

onde:

$\alpha=$ ângulo de face do talude.

$\beta=$ mergulho da descontinuidade.

$\phi \mathrm{j}=$ ângulo de atrito da descontinuidade.

Outra condição cinemática definida foi a de que a direção da descontinuidade não fizesse um ângulo maior do que $15^{\circ}$ com a direção do talude, caso contrário haveria um "engastamento" do conjunto de lâminas, que não estariam livres para tombar.

Essas condições necessárias de deslizamento das lâminas não são, por si só, um indicativo suficiente de que o tombamento flexural vá acontecer, porque não levam em conta o equilíbrio de forças atuando em cada uma delas. Pode existir o caso em que, mesmo sendo satisfeita a condição cinemática, não ocorra o tombamento.
Adhikary et al. (1997) fizeram um comparativo entre as condições-limites de tombamento flexural, definidas por Goodman e Bray (1976), e os resultados que obtiveram, experimentalmente, em modelos físicos submetidos à ação de força centrífuga (Figura 2).

O gráfico mostra as condições de equilíbrio de forças como pontos no gráfico. As condições cinemáticas necessárias de Goodman e Bray (1976), por sua vez, aparecem em linhas cheias. Notase que, para um mesmo arcabouço geomecânico, representado por uma altura fixa e valores dados de $\beta$ e $\phi j$, o equilí-

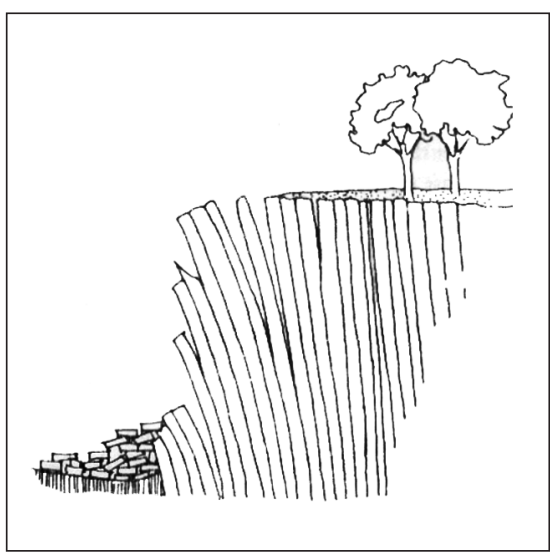

Figura 1 - llustração do mecanismo de tombamento flexural e detalhe do movimento entre as lâminas (Hoek \& Bray, 1977).

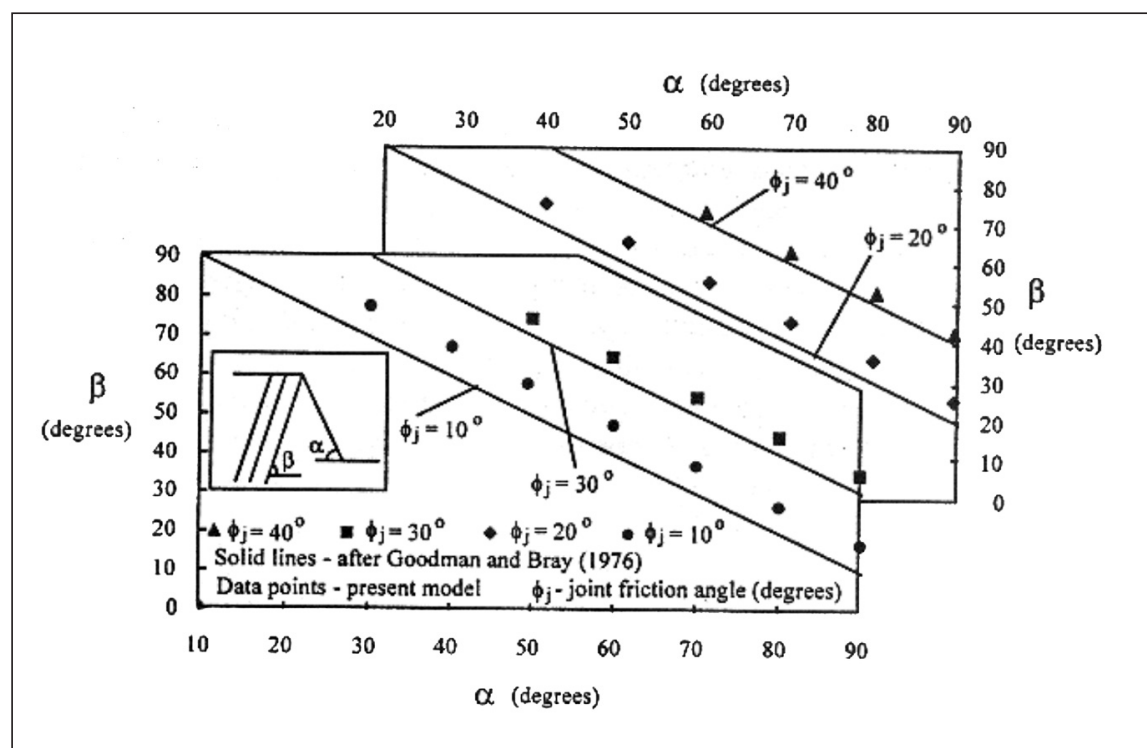

Figura 2 - Comparativo entre as condições limites de tombamento flexural de Adhikary et al., 1997 e Goodman e Bray, 1976 (Adhikary et al., 1997). 
brio de forças sempre indica, para o ângulo de face do talude na situação limite ( $\alpha=$ abscissas do gráfico), um valor mais elevado. Portanto as condições cinemáticas são conservadoras, indicando que ocorrem taludes estáveis mais inclinados do que aqueles indicados pelas mesmas.

Para Sjöberg (1999), a ocorrência de ruptura por tombamento em taludes de grande escala é governada principalmente por três fatores:

- Resistência e orientação das descontinuidades.

- Resistência da rocha intacta.

- Deformabilidade (ou rigidez) do maciço rochoso.

Para o tombamento ocorrer, primeiramente deve haver deslizamento ao longo das descontinuidades, o que irá depender da orientação e da magnitude da tensão cisalhante existente antes da ruptura. As orientações possíveis para as tensões cisalhantes máximas são, segundo o círculo de Mohr, a $\pm 45^{\circ}$ da tensão principal $\sigma 1$, que, nesse caso, é subparalela à face do talude (a tensão principal mínima $\sigma 3$ é, portanto, perpendicular à mesma e de valor praticamente desprezível). Assim sendo, as lâminas terão maior tendência ao deslizamento quanto menor for o ângulo formado entre elas e a direção das tensões cisalhantes máximas. Tal ângulo é, por sua vez, função das inclinações do talude e do mergulho da descontinuidade principal.

No plano dimensional, normal ao talude, tem-se:

$$
\tau_{\max }=\frac{\sigma_{1-} \sigma_{3}}{2}
$$

A Figura 3 mostra a diferença entre as tensões principais $(\sigma 1-\sigma 3)=2 \tau_{\text {máx }}$ . O que se observa é que as máximas tensões cisalhantes serão maiores no pé do talude e que, portanto, onde há o maior potencial para que o deslizamento entre as lâminas se inicie é naquele ponto, como realmente acontece.

A condição cinemática definida por Goodman e Bray (1976) é aplicável so- mente próximo à face do talude. Na medida em que se distancia da face, a tensão principal máxima $(\sigma 1)$ muda de orientação até se tornar paralela à tensão virgem horizontal ( $\sigma$ h) (Sjöberg, 1999). Ao mesmo tempo, a tensão principal menor $(\sigma 3)$, desprezível nas proximidades da face, aumenta seu valor. Como conseqüência, o deslizamento das descontinuidades fica mais difícil, porque a tensão normal ao plano da descontinuidade aumenta e a tensão cisalhante diminui (Figura 4).

\section{Estudo numérico de tombamento flexural}

Foram realizadas um total de 255 análises, correspondendo a uma combinação de geometrias de talude com ângulos que variaram de $30^{\circ}$ a $60^{\circ}$ e alturas de 50 a $200 \mathrm{~m}$, de ângulos da foliação, variando de $40^{\circ}$ a $80^{\circ}$, e de quatro diferentes classes geomecânicas de maciços.

No programa FLAC (Fast Lagrangian Analysis of Continua) utilizou-se o

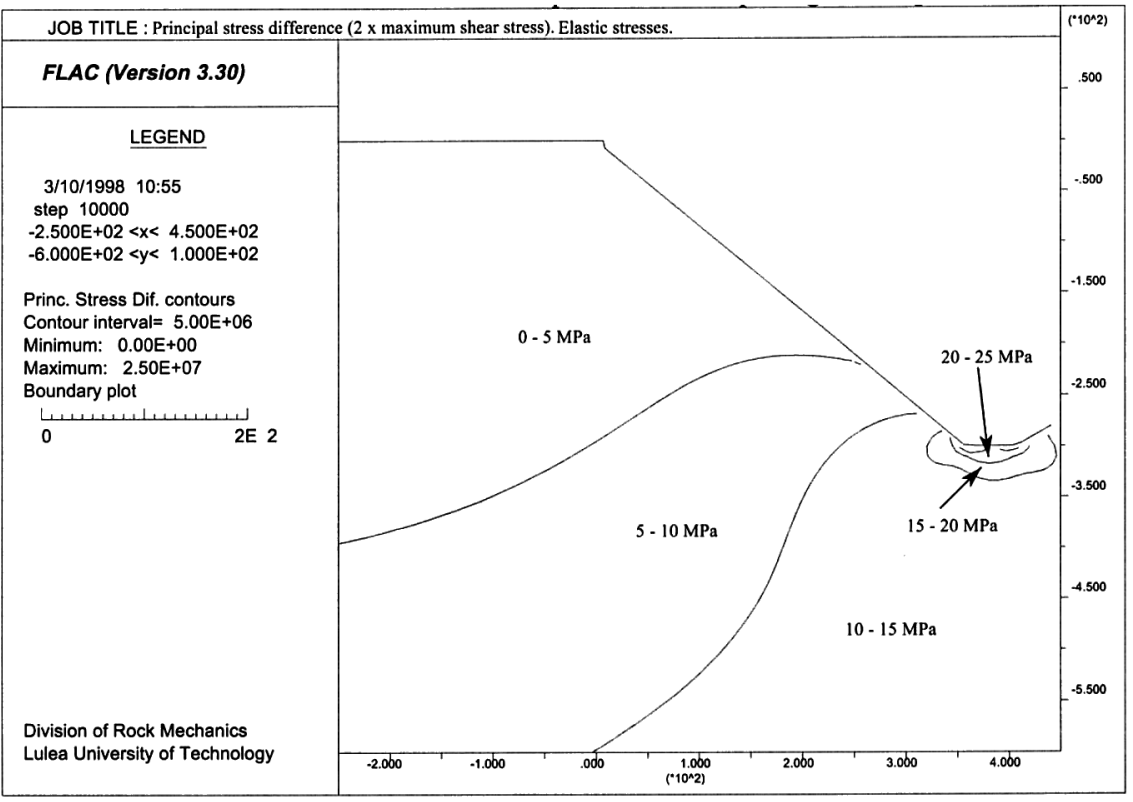

Figura 3 - Diferença calculada, usando o FLAC, das tensões principais (elásticas) para um talude de $300 \mathrm{~m}$ de altura com um ângulo de $40^{\circ}$ (Sjöberg, 1999).

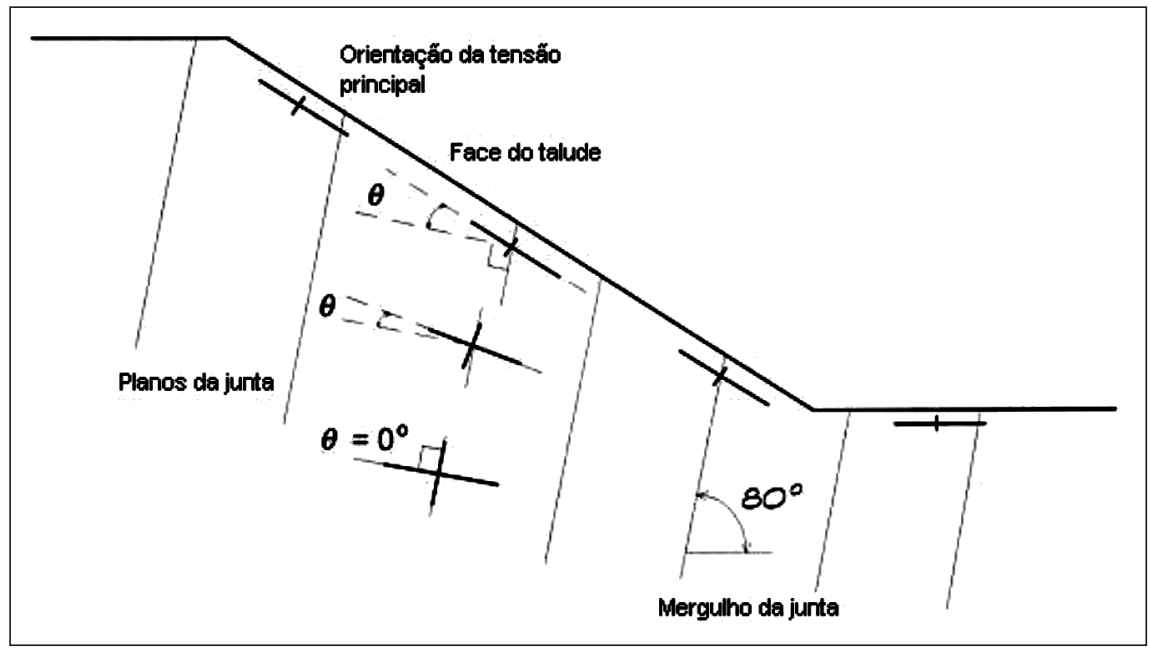

Figura 4 - Ilustração mostrando o ângulo entre a normal do plano da descontinuidade e a tensão principal maior, $\sigma 1$, e como esse ângulo muda à medida que se afasta da face do talude (Sjöberg, 1999). 
modelo elasto-plástico de juntas ubíquas. Para esse modelo, se faz necessário o conhecimento de vários parâmetros do maciço rochoso, a saber:

$\mathrm{d}=$ densidade do material $\left(\mathrm{g} / \mathrm{cm}^{3}\right)$.

$\phi=$ ângulo de atrito da rocha.

di $=$ dilatância.

$\mathrm{c}=$ coesão da rocha $(\mathrm{KPa})$.

$\mathrm{t}=$ resistência à tração da rocha $(\mathrm{KPa})$.

$\phi j=$ ângulo de atrito da junta ubíqua.

dij = dilatância da junta ubíqua.

cj = coesão da junta ubíqua $(\mathrm{KPa})$.

$\mathrm{t} \mathrm{j}=$ resistência à tração da junta ubíqua

$(\mathrm{KPa})$.

ja $=$ mergulho da junta ubíqua.

$\mathrm{E}=$ módulo de elasticidade $(\mathrm{GPa})$.

$v=$ coeficiente de Poison.

\subsection{Definição de parâmetros geotécnicos}

A definição dos parâmetros geotécnicos utilizados nesse trabalho baseouse em pesquisa bibliográfica sobre maciços semelhantes, sendo o trabalho mais recente o de Castro (2004) e na experiência adquirida em trabalhos e estudos de estabilidade envolvendo taludes em filitos e xistos nas minas de Gongo SocoCVRD (Golder, 2003), Córrego do Sítio-Anglogold (Golder, 2003), PicoMBR (SBC, 2002), Pau Branco-V\&M (SBC, 2000) e Timbopeba-CVRD (SBC, 1999).

A Tabela 1 apresenta um resumo de todos os parâmetros utilizados, abrangendo diferentes classes geomecânicas de maciço.
Os parâmetros de densidade e resistência do maciço foram obtidos do trabalho de Castro (2004), que realizou uma ampla pesquisa bibliográfica sobre estudos de estabilidade de taludes de várias minas no Quadrilátero Ferrífero (Q.F.) e sintetizou em gráficos os dados obtidos para diversos litotipos e classes de maciço. Com relação à resistência à tração da rocha intacta $(\mathrm{t})$, Sjöberg (1999) e outros autores consideraram, em suas análises, o seu valor igual a zero, o que é um pouco conservador. Nas análises desse trabalho, considerou-se a resistência à tração como sendo $\sigma_{\mathrm{ci}} / 10$, sendo $\sigma_{c i}=\frac{2 c \cos \phi}{1-\operatorname{sen} \phi}$ pelo critério de Mohr-Coulomb.

Para a junta ubíqua, que representa a descontinuidade principal (estratificação ou foliação), esse parâmetro (jt) possui um valor baixo o suficiente para ser desprezado para efeitos práticos. Já para os parâmetros de resistência da mesma, utilizaram-se valores de atrito e coesão baseados na experiência adquirida em estudos e retroanálises de estabilidade em maciços de filito e xisto no Q.F. nas minas citadas anteriormente.

As dilatâncias do maciço (di) e da junta ubíqua (jdi) foram consideradas como zero, por ser esta uma suposição conservadora (a favor da segurança), por não se terem indicações de literatura à respeito e por ser, no caso da foliação, uma consideração razoável, uma vez que as interfaces praticamente não apresen- tam rugosidade, que, no caso, é o que determina a dilatância.

Com relação aos parâmetros de deformabilidade do maciço, existem poucos resultados de ensaios em xistos e filitos no Q.F. Os valores utilizados foram extraídos da literatura (Rocscience, 2001; Sjöberg, 1999; Itasca, 1995) e correspondem somente aos maciços classe II/I (rocha) e classe V (solo). Para os maciços intermediários, foi feita uma interpolação linear desses dados de tal forma a obedecer uma ordem de grandeza entre as classes e, assim, não comprometer qualitativamente os resultados obtidos.

\subsection{Estado de tensões virgens}

Como quase não há estudos publicados sobre o estado de tensões virgens na região, adotou-se, como premissa, um valor de $\mathrm{k}=1.5$, entretanto esse valor pode ser maior, podendo chegar a $\mathrm{k}=2,0$, ou mais, dependendo das condições e esforços tectônicos a que foi submetido o maciço.

Retroanálises utilizando o $F L A C$, de um talude em quartzito na mina de Timbopeba (CVRD), em Mariana, realizadas por Figueiredo e Lana (1999), indicaram um valor de $\mathrm{k}=1$. Entretanto, a experiência internacional sumarizada por Hoek e Brown (1980) sugere que, a profundidades inferiores a $400 \mathrm{~m}$, o valor de k é geralmente maior que um. Daí o valor selecionado.

Tabela 1 - Parâmetros geotécnicos para as diferentes classes de maciço.

\begin{tabular}{|c|c|c|c|c|c|c|c|c|c|c|c|c|}
\hline Classe & $\begin{array}{c}\mathrm{PE} \\
\left(\mathrm{KN} / \mathrm{m}^{3}\right)\end{array}$ & $\begin{array}{c}\phi \\
\left(^{\circ}\right)\end{array}$ & $\begin{array}{c}\mathrm{C} \\
(\mathrm{KPa})\end{array}$ & $\begin{array}{c}t \\
(\mathrm{KPa})\end{array}$ & $\begin{array}{c}E \\
(\mathrm{GPa})\end{array}$ & $v$ & $\begin{array}{l}\text { di } \\
\left({ }^{\circ}\right)\end{array}$ & $\begin{array}{l}\text { ja } \\
\left({ }^{\circ}\right)\end{array}$ & $\begin{array}{l}\mathrm{j} \phi \\
\left(^{\circ}\right)\end{array}$ & $\begin{array}{c}\mathrm{jc} \\
(\mathrm{KPa})\end{array}$ & $\begin{array}{c}\text { jt } \\
(\mathrm{KPa})\end{array}$ & $\begin{array}{l}\text { jdi } \\
\left({ }^{\circ}\right)\end{array}$ \\
\hline V & $18,5 \pm 1,5$ & $25 \pm 2$ & $50 \pm 20$ & 16 & 0,27 & 0,25 & 0 & 40 a 80 & $22 \pm 2$ & $10 \pm 10$ & 0 & 0 \\
\hline IV & $20 \pm 1,5$ & $28 \pm 2$ & $150 \pm 20$ & 50 & 0,5 & 0,25 & 0 & 40 a 80 & $25 \pm 2$ & $50 \pm 20$ & 0 & 0 \\
\hline III & $21 \pm 1,5$ & $34 \pm 2$ & $230 \pm 20$ & 86,5 & 2 & 0,25 & 0 & 40 a 80 & $25 \pm 2$ & $50 \pm 20$ & 0 & 0 \\
\hline $\mathrm{II} / \mathrm{I}$ & $22 \pm 1,5$ & $42 \pm 2$ & $520 \pm 20$ & 233 & 11 & 0,25 & 0 & 40 a 80 & $25 \pm 2$ & $50 \pm 20$ & 0 & 0 \\
\hline
\end{tabular}




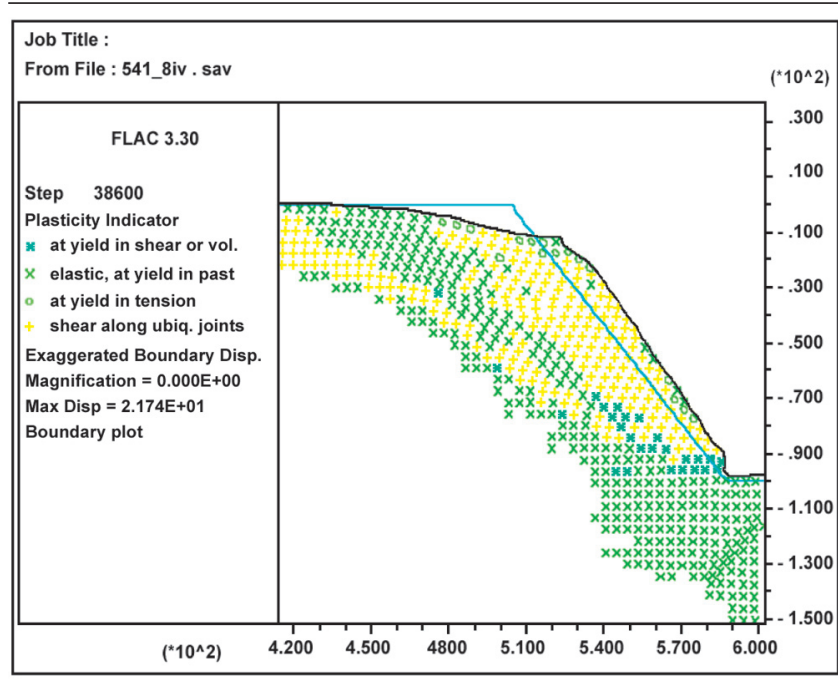

Figura 5 - Indicadores de plasticidade mostrando o cisalhamento ao longo das juntas ubíquas e alguns pontos no pé do talude sofrendo cisalhamento. Notar a diferença entre a superfície inicial e após a ruptura. Talude com $100 \mathrm{~m}$ de altura, ângulo médio de $50^{\circ}$, foliação mergulhando $80^{\circ}$ e um maciço classe IV.

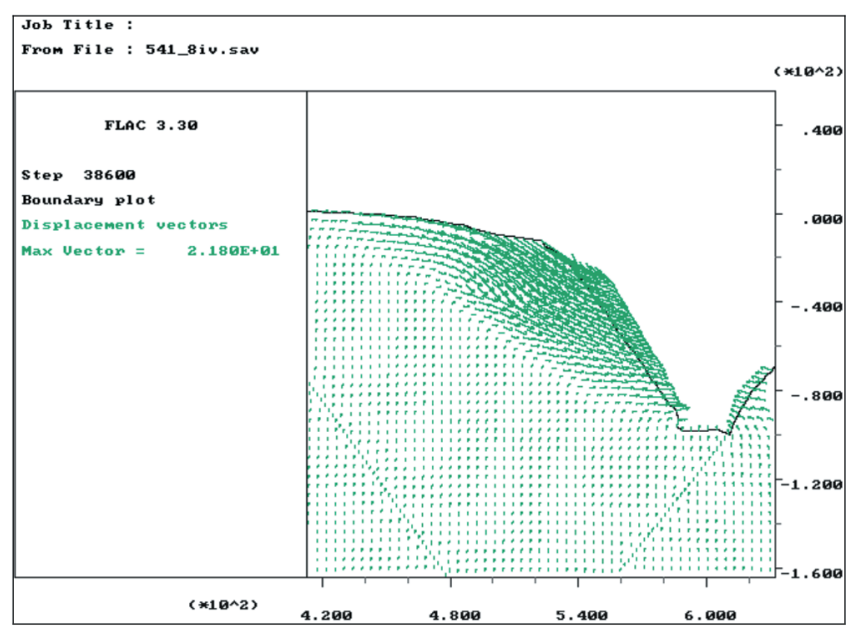

Figura 6 - Vetores de deslocamento indicando uma movimentação muito maior da crista em relação ao pé do talude.

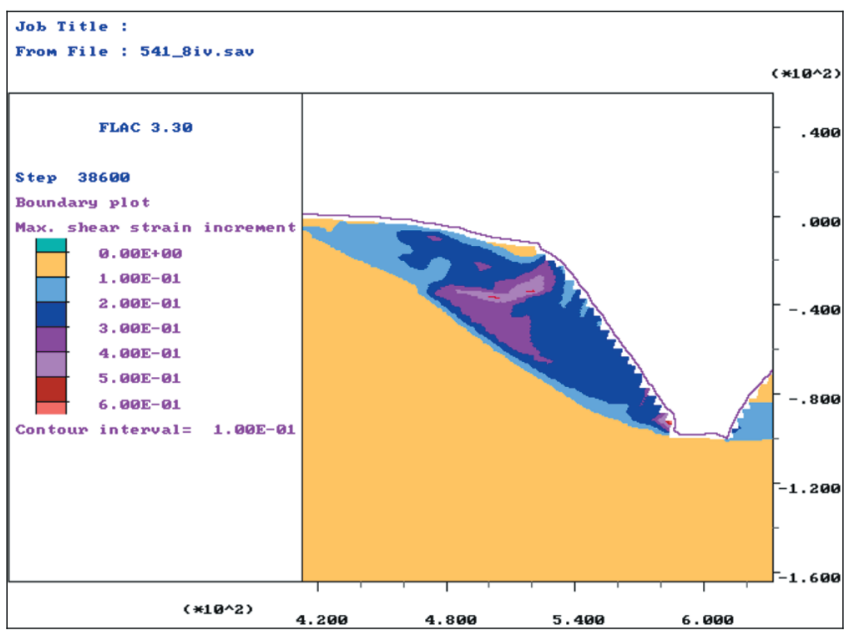

Figura 7 - Contorno dos incrementos de deformação cisalhante mostrando nitidamente a massa rompida.

\subsection{Análises tensão-deformação}

Para se avaliar o comportamento do maciço simulado, observaram-se os indicadores de plasticidade, o campo dos vetores de deslocamento, o incremento da deformação cisalhante e os isocontornos de tensões desviadoras (diferenças entre as componentes principais).

Através da análise desses vários indicadores, foi possível determinar, em cada uma das análises, para quais geometrias os taludes apresentaram ruptura por tombamento flexural. Um exemplo é mostrado nas Figuras 5, 6 e 7.

\subsection{Cartas de estabilidade}

Uma vez analisadas todas as informações geradas, foi possível condensá-las em três cartas de estabilidade (Figuras 8 e 9) para as classes de maciço II, III e IV, com curvas que delimitam zonas estáveis e instáveis ao tombamento flexural para diferentes alturas de talude. Nessas cartas, também foram lançadas as retas correspondentes ao critério cinemático de Goodman e Bray (1976).

O que se pôde perceber é que o critério de Goodman e Bray pode ser conservador, como já demonstrado por Adhikary et al. (1997), mas, dependendo da altura do talude, ele se torna extremamente arrojado. Isso se deve ao fato de que a altura do talude atua como um fator instabilizador. Essa instabilização se daria devido ao aumento da tensão diferencial atuante nas lâminas rochosas (não levado em conta por Goodman \& Bray).

Um talude normalmente é constituído por diversas classes de maciço. Para se utilizarem as cartas de estabilidade, será necessário sempre verificar as alturas a partir da base de cada classe de maciço até à superfície. Para o maciço que se encontra no pé do talude, deve-se pegar a altura total do mesmo e consultar a carta correspondente à classe lá encontrada, porque as tensões ali atuantes correspondem à da altura total. Para um maciço em posição intermediária no talude, deve-se pegar a altura a partir da base do mesmo (porque as tensões atuantes nesse ponto correspondem a essa altura) e consultar a carta da classe correspondente e, assim, sucessivamente, se houver mais classes. A partir da composição desses ângulos obtém-se um ângulo global para o talude.

\section{Considerações finais}

Desse trabalho, pôde-se perceber que, realmente, o método numérico se apresenta como o mais adequado para o estudo desse tipo de mecanismo, pois permite a modelagem de grandes deformações. A partir dessas análises, puderam-se gerar as cartas de estabilidade para diferentes alturas e classes de maciço. 
Estudo computacional do mecanismo de tombamento flexural em filitos

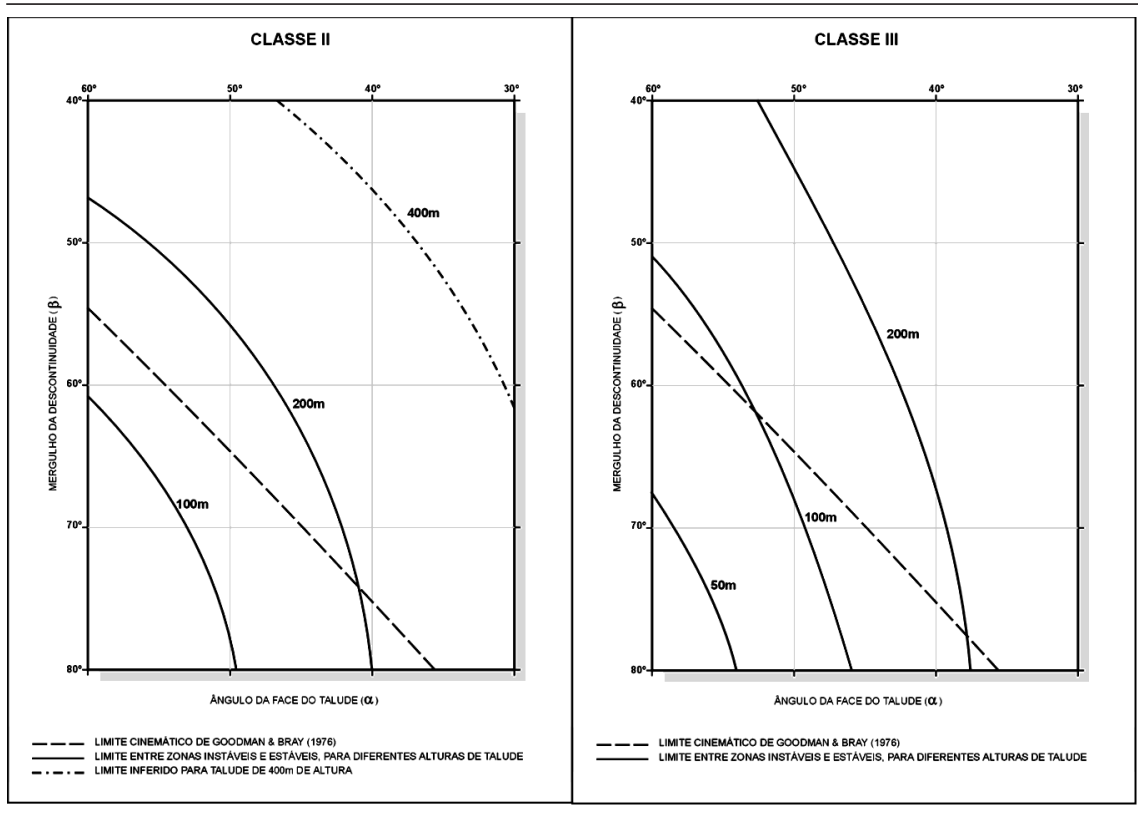

Figura 8 - Ábaco de estabilidade para o maciço classe II e III.

O uso dessas cartas, como método de avaliação da estabilidade de taludes sujeitos a tombamento, deve ser em caráter preliminar, uma vez que as análises numéricas foram levadas a termo considerando os taludes como meios homogêneos, constituídos por filitos/xistos em condição drenada. Como a geologia de uma região determinada pode ser complexa e também devido ao fato de os parâmetros adotados nesse trabalho corresponderem a um valor médio, encontrado com base, tanto na literatura, quanto em resultados de ensaios diversos, os resultados têm um valor muito mais qualitativo do que quantitativo.

Para um aprimoramento dos resultados apresentados, sugere-se que estudos futuros sejam realizados, considerando a influência da variação do $\mathrm{k}$ (tensões iniciais), bem como a influência de diferentes níveis d'água nos resultados apresentados.

\section{Referências bibliográficas}

ADHIKARY, D., DYSKIN, A.V., JEWELL, R.J., STEWART, D.P. A study of the mechanism of flexural toppling failure of rock slopes. Rock Mech. Rock Engng. v. 30, n. 2, p.7593, 1997.
AYDAN, Ö., KAWAMOTO, T. The stability of slopes and underground openings against flexural toppling and their stabilization. Rock Mech. Rock Engng. v. 25, n. 3, p.143-165, 1992.

CASTRO, W. J. Sintese de estudos de estabilidade de taludes - minas de minério de ferro do Quadrilátero Ferrífero. Ouro Preto: Departamento de Engenharia Civil, EM/ UFOP, 2004. (Dissertação de Mestrado - em andamento).

FIGUEIREDO, R. P. Aplicações da técnica de relaxação dinâmica à solução de problemas geotécnicos. Rio de Janeiro: Departamento de Engenharia Civil, PUC-RIO, 1990. (Dissertação de Mestrado).

FIGUEIREDO, R. P., LANA, M. S. Análise da estabilidade do talude final na mina de Timbopeba. REM: Revista da Escola de Minas. v. 52, n. 4 (out-dez), p. 239-244, 1999.

GOLDER. Estudo de estabilidade e dimensionamento de taludes da cava de expansão da Mina de Gongo Soco, Barão de Cocais. 2003. (Relatório interno).

GOLDER. Estudos geotécnicos do talude oeste da Cava de Cachorro Bravo, Mineração Córrego do Sítio, Santa Bárbara. 2003. (Relatório interno).

GOODMAN, R. E., BRAY, J. W. Toppling of Rock Slopes. Proc. Rock Eng. For Foundations and Slopes, boulder. 2, p.201-234, 1976.

HOEK, E., BRAY, J. W. Rock slope engineering. Cambridge: The Institution of Minning and Metallurgy, 1977.

HOEK, E. \& BROWN, E. Underground excavations in rock. London: IMMM, 1980. $527 \mathrm{p}$.

ITASCA. Manual do FLAC. 1995.

PRITCHARD, M. A., SAVIGNY, K. W. Numerical modelling of toppling. Can. Geotech. J. n. 27, p. 823-834, 1990.

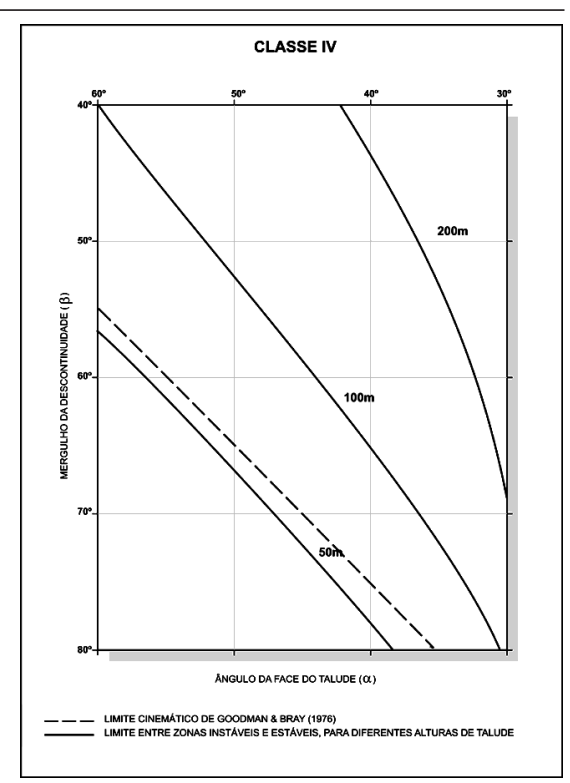

Figura 9 - Ábaco de estabilidade para o maciço classe IV.

SBC. Estudos de estabilidade de taludes da Mina do Pico, MBR. 2002. (Relatório interno).

$\mathrm{SBC}$. Estudo de estabilidade do talude oeste da mina Pau Branco, V\&M. 2000. (Relatório interno).

SBC. Estudos de estabilidade e reavaliação do dimensionamento preliminar dos taludes Oeste, ETA e Sudeste da Mina de Timbopeba, CVRD. 1999. (Relatório interno).

SJÖBERG, J. Analysis of large scale rock slopes. Sweden: Division of Rock Mechanics - Luleå University of Technology, 1999. (Doctoral Thesis).

SHIMIZIU, Y., AYDAN, Ö., KAWAMOTO, T. Several toppling failures in Japan and their back analysis. Assessment and Prevention of Failure Phenomena in Rock Engineering. PAPAMEHMETOĐLU et al. (eds). Balkema, Rótterdam: 1993. p. 879-885.

ZANBAK, C. Design charts for rock slopes susceptible to toppling. J. Geotech. Engng. v. 109, n. 8, p. 1039-1062, 1983.

\section{Artigo recebido em 28/06/2004 e} aprovado em 03/03/2005.

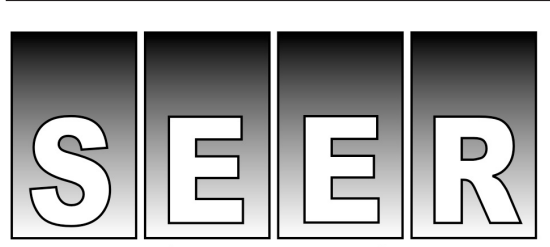

SISTEMAA ELETRONNICO DE EDITORAGLOAO DE REVISTAS
A nova maneira de enviar um trabalho para a REM 